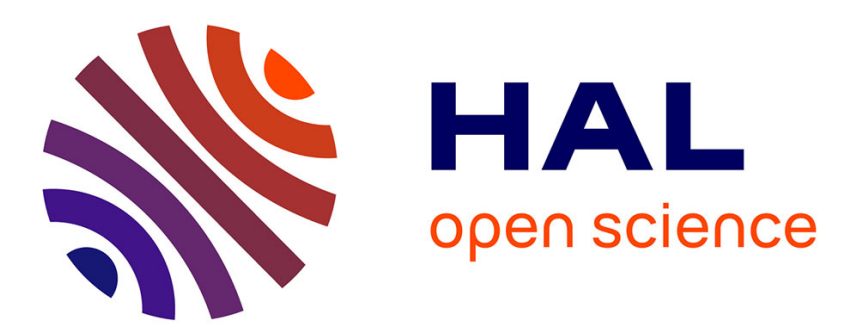

\title{
Reversible Assembly of Microgels by Metallo-Supramolecular Chemistry
}

Julien Es Sayed, Cédric Lorthioir, Philippe Banet, Patrick Perrin, Nicolas

Sanson

\section{- To cite this version:}

Julien Es Sayed, Cédric Lorthioir, Philippe Banet, Patrick Perrin, Nicolas Sanson. Reversible Assembly of Microgels by Metallo-Supramolecular Chemistry. Angewandte Chemie International Edition, 2020, 59 (18), pp.7042-7048. 10.1002/anie.201915737 . hal-02555605

\section{HAL Id: hal-02555605 \\ https://hal.science/hal-02555605}

Submitted on 27 Apr 2020

HAL is a multi-disciplinary open access archive for the deposit and dissemination of scientific research documents, whether they are published or not. The documents may come from teaching and research institutions in France or abroad, or from public or private research centers.
L'archive ouverte pluridisciplinaire HAL, est destinée au dépôt et à la diffusion de documents scientifiques de niveau recherche, publiés ou non, émanant des établissements d'enseignement et de recherche français ou étrangers, des laboratoires publics ou privés. 


\title{
Reversible Assembly of Microgels by Metallo-Supramolecular Chemistry
}

\author{
Julien Es Sayed, Cédric Lorthioir, Philippe Banet, Patrick Perrin,* and Nicolas Sanson*
}

\begin{abstract}
The combination of supramolecular chemistry and soft colloids as microgels represents an ambitious way to develop multi-versatile colloidal assemblies. Hereafter, terpyridine-functionalized poly( $N$-isopropylacrylamide) (PNiPAM) microgel building blocks are shown to undergo an assemblefreeze-disassemble process. The microgel assemblies, which are controlled by monitoring the attractive and repulsive potentials between the soft colloidal particles, are then frozen by forming inter-particle metal-terpyridine bis-complexes upon addition of the metallic cation (such as $\mathrm{Fe}^{I I}, \mathrm{Co}^{I I}$ ). By oxidation of the metal-terpyridine bis-complex links, the aggregates open up, which is due to the complex dissociation releasing the connected particles in the form of single microgels. We extended our work to the development of $1 D$ filaments and $2 D$ membranes materials made of soft particles connected via supramolecular chemistry.
\end{abstract}

\section{Introduction}

Assembly of colloidal particles is a paramount challenge. Understanding the collective behavior of colloidal particles paves the way to unravelling the crystal nucleation and growth mechanisms by assimilating one particle to a big atom, or to the elaboration of so-called colloidal molecules or supracolloids. ${ }^{[1]}$ To this end, the fine-tuning of particle assembly first requires precise control over the potentials acting on it. Besides, the particle assembly can be directed by designing geometrically and/or chemically anisotropic building blocks leading to so-called patchy particles. ${ }^{[2]}$ Recently, research has been oriented towards assembly of deformable and versatile colloids named microgels, which are extensively studied as soft colloidal particles made of a solvent swollen

[*] Dr. J. Es Sayed, Prof. P. Perrin, Dr. N. Sanson

Soft Matter Sciences and Engineering, ESPCI, PSL University,

Sorbonne Université, CNRS

10 rue Vauquelin, 75231 Paris Cedex 05 (France)

E-mail: patrick.perrin@espci.fr nicolas.sanson@espci.fr

Dr. C. Lorthioir

Laboratoire de Chimie de la Matière Condensée de Paris

Sorbonne Université, CNRS, Collège de France

4 Place Jussieu, 75005 Paris Cedex 05 (France)

Dr. P. Banet

Laboratoire de Physicochimie des Polymères et des Interfaces CY Cergy Paris Université

5 Mail Gay Lussac, Site de Neuville, 95000 Cergy Pontoise Cedex (France) network of crosslinked polymer chains. ${ }^{[3]}$ Their chemical nature, which can be adapted on-demand to introduce specific functionalities, and their soft hairy structure, allowing them to come into contact without irreversible aggregation, make microgels outstanding candidates to form colloidal assemblies. ${ }^{[4]}$ The versatility of building block microgel particles can be enhanced by coupling it with supramolecular chemistry, paving the way to the design of selective or reversible colloidal assemblies. For instance, host-guest supramolecular chemistry has been widely used to selectively assemble microgels functionalized by $\beta$-cyclodextrins as host with microgels bearing either adamantane, azobenzene or ferrocene moieties as guests. ${ }^{[5]}$ Another type of supramolecular interactions, which appears to be well-suited to perform supramolecular assemblies of microgels, is metal-ligand coordination chemistry. ${ }^{[6]}$ This chemistry has been widely used and studied in the field of polymer chemistry to design metallo-supramolecular polymers with well-defined architectures. $^{[7]}$ However, metal-ligand chemistry remains scarcely used in the field of colloidal assembly. ${ }^{[8]}$ For instance, Gerth et al. connected silica particles by the intermediate of terpyridine-functionalized PEO chains adsorbed onto their surface. They showed that the gelation of these suspensions can be triggered by adding cobalt(II) cations. ${ }^{[\mathrm{bb}]}$ Recently, Lee et al. investigated the rheological properties of macrogels resulting from the gelation of thermoresponsive microgels functionalized with terpyridine moieties through the addition of different metal ions. ${ }^{\left[{ }^{[c]}\right]}$ To the best of our knowledge, the elaboration of reversible microgel assemblies using metallosupramolecular chemistry has not yet been reported.

Hereafter, we describe a straightforward assemblefreeze-disassemble route to design bulk assemblies of thermoresponsive microgels in aqueous dispersions (Scheme 1). Our strategy is first based on the synthesis of well-defined terpyridine-functionalized thermoresponsive microgels used as building blocks. Then, the control over the assembly of PNiPAM microgels involves two essential prerequisites: 1) the terpyridine ligands (Tpy) need to be accessible when adding the metal cation to establish metallo-supramolecular connections between microgels; 2) the probability of contact between microgels needs to be sufficiently high to develop short-range inter-particle supramolecular links as the metal cation is introduced in the aqueous dispersion. Microgels can be considered, at least at first glance, as classical hard colloids, meaning that their proximity in solution is controlled by a balance between attractive and repulsive potentials and by the concentration of the dispersion. Consequently, the average distance between microgels can certainly be adjusted by varying the volume fraction $(\varphi)$ and by modulating both the repulsive interactions by adding salt and the short-range 
Individualized microgels

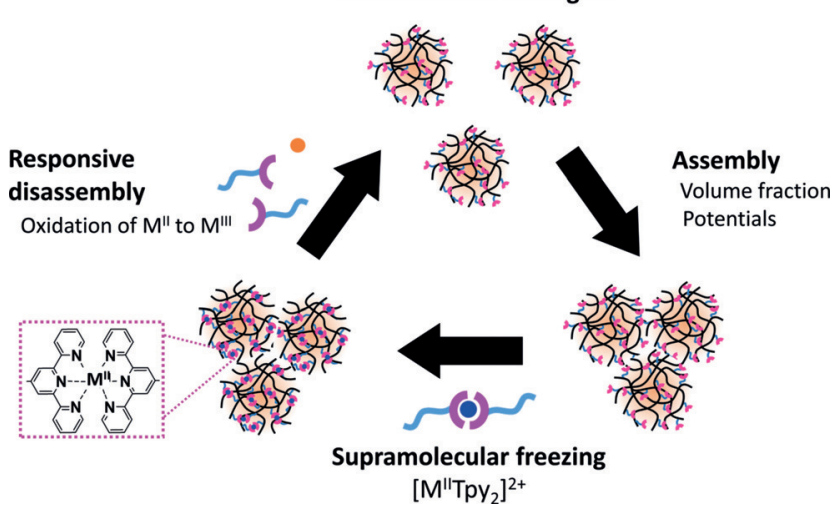

Scheme 1. General assemble-freeze-disassemble strategy for the design of reversible microgel assemblies by metallo-supramolecular chemistry using MG-Tpy microgels as building blocks. Starting from well-dispersed microgels, the assemblies are dictated by adjusting both the volume fraction and the interaction potentials between them. Then, the formation of metallo-supramolecular complexes, $\left[\mathrm{M}^{\mathrm{II}} \mathrm{Tpy}_{2}\right]^{2+}$, enables the freezing of the assembled microgels. Finally, the disassembly of the formed microgel assemblies can be triggered by the oxidation of the metal cation trapped in the bis-terpyridine complex leading to individual microgels.

attractive depletion potential originating by adding depletant molecules in solution. Then, the $\left[\mathrm{M}^{\mathrm{II}} \mathrm{Tpy}_{2}\right]^{2+}$ complexes formed upon addition of the metal cation $\left(\mathrm{Fe}^{\mathrm{II}}\right.$ or $\left.\mathrm{Co}^{\mathrm{II}}\right)$ act as supramolecular links between microgels to freeze the formed assemblies. We also take advantage of the supramolecular nature of the $\left[\mathrm{M}^{\mathrm{II}} \mathrm{Tpy}_{2}\right]^{2+}$ links to use oxidation as an original stimulus to break up the $\left[\mathrm{M}^{\mathrm{II}} \mathrm{Tpy}_{2}\right]^{2+}$ complexes and disassemble the connected microgels into individual microgel building blocks (Scheme 1). This work reports on a promising way to generate new stimuli-responsive microscale and macroscale materials using microgels as functionalized building blocks. Although our work mainly focuses on the 3D assemblies, we show that our assemble-freezedisassemble concept can readily be applied to develop 1D and 2D materials using microgel building blocks.

\section{Results and Discussion}

\section{Microgel Building Blocks}

Terpyridine-functionalized and thermoresponsive microgels (MG-Tpy) were synthesized in a one-step synthesis in water by surfactant-free dispersion copolymerization of $\mathrm{N}$ isopropylacrylamide (NiPAM) as main monomer and poly(ethylene glycol) monomethacrylate end-modified by a terpyridine group (PEGMA-Tpy) as comonomer ( $0.25 \mathrm{~mol} \%$ vs. NiPAM) in presence of a chemical crosslinker, $N, N^{\prime}$-methylenebisacrylamide (MBA, $2 \mathrm{~mol} \%$ vs. NiPAM; Scheme 2). Labeled microgels with fluorescein (MG-TpyF) or rhodamine B (MG-TpyR) monomers have also been synthesized for visualization by confocal laser scanning microscopy (CLSM; Supporting Information, Table S1). Before using MG-Tpy microgels as building blocks for colloidal assemblies, the

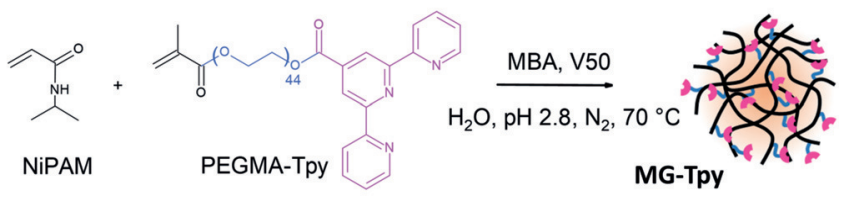

Scheme 2. One-step synthesis of terpyridine-modified thermoresponsive microgels, MG-Tpy. Microgels are used as building blocks for complex assemblies induced by metallo-supramolecular chemistry. The synthesis of the PEGMA-Tpy macromonomer is described in the Supporting Information, Figures S1, S2.

chemical composition, thermal behavior, colloidal stability, and morphology of the microgels were investigated using dynamic light scattering (DLS), nuclear magnetic resonance (NMR), scanning electron microscopy (SEM), UV/Vis spectroscopy, and zetametry. Our results show that microgels with terpyridine groups have been obtained in a one-step synthesis. Their behavior in water is similar to that of the pure NiPAM microgels (Figure $1 \mathrm{a}, \mathrm{b}$ ). Owing to the possible protonation of terpyridine groups in acidic conditions, MG-Tpy microgels

a

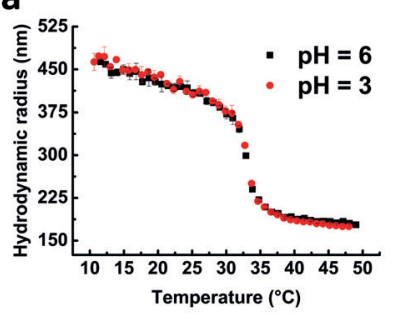

C $0.6[280 \mathrm{~nm}$

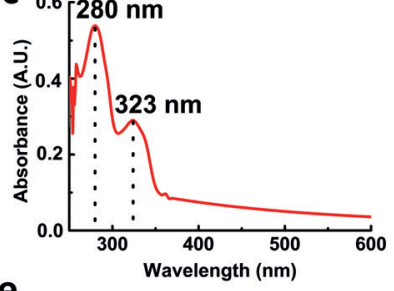

$e_{-\mathrm{CH}}-\mathrm{CH}_{2}-\mathrm{CH}_{2}-\mathrm{O}$

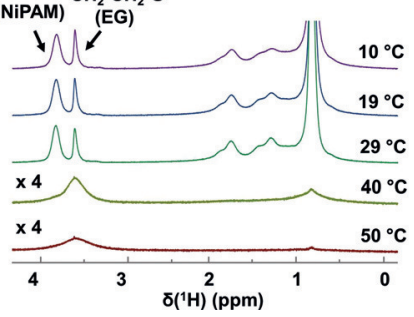

Figure 1. Characterization of terpyridine-modified thermoresponsive NiPAM microgels MG-Tpy. a) Hydrodynamic radius as a function of temperature at $\mathrm{pH} 6$ and $\mathrm{pH}$ 3. b) Electrophoretic mobility as a function of temperature at $\mathrm{pH} 6$ and $\mathrm{pH}$ 3. c) Absorbance of synthesized MG Tpy microgels (DMSO). d) SEM image of MG-Tpy microgels (scale bar: $5 \mu \mathrm{m}$ ). e) Temperature dependence of ${ }^{1} \mathrm{H}$ NMR spectra of MG-Tpy in $\mathrm{D}_{2} \mathrm{O}$ at $\mathrm{pH}$ 6. f) Temperature dependence of the fraction of mobile NiPAM and PEGMA-Tpy units, $f_{\text {NiPAM }}$ and $f_{\text {EG }}$, as determined at $\mathrm{pH} 6$. The fractions were calculated using the area of the NMR peak assigned to either the isopropyl $\mathrm{CH}$ protons of the NiPAM units or the $\mathrm{CH}_{2} \mathrm{CH}_{2} \mathrm{O}$ protons of the PEGMA-Tpy units normalized by the area value measured at $T=1{ }^{\circ} \mathrm{C}$. 
were characterized both at $\mathrm{pH} 3$ and $\mathrm{pH} 6 .^{[9]}$ Irrespective of $\mathrm{pH}$, the MG-Tpy microgels exhibit a decrease of the hydrodynamic radius throughout the polymer phase transition with a volume phase transition temperature (VPTT) around $33^{\circ} \mathrm{C}$ whereas the value of the electrophoretic mobility increases owing to the presence of cationic initiator. Such features are characteristics of thermoresponsive pure NiPAM microgels (Figure 1a,b; Supporting Information, Figure S3). The presence of terpyridine groups in the microgel network and its quantification were established by UV/Vis spectroscopy, with absorption bands at 280 and $323 \mathrm{~nm}$ being characteristic of the terpyridine groups (Figure $1 \mathrm{c}$ ), and ${ }^{1} \mathrm{H}$ NMR spectroscopy (Supporting Information, Figure S4 and Table S2). Both methods are in excellent agreement as they give a similar amount of terpyridine groups incorporated in the microgel network evaluated at $2.6 .10^{-5} \mathrm{~mol}$ per gram of microgel. From SEM observations, microgels exhibit a spherical shape with a low polydispersity index (PDI $<0.1$; Figure $1 \mathrm{~d}$ ). The localization of the terpyridine groups into the microgel network is an important question, as microgel connection requires their accessibility. To probe the distribution of the Tpy functions, ${ }^{1} \mathrm{H}$ NMR spectra of MG-Tpy microgels in $\mathrm{D}_{2} \mathrm{O}$ were recorded at different equilibrium temperature between 1 and $57^{\circ} \mathrm{C}$ (Figure 1e). The peaks related either to the isopropyl $\mathrm{CH}$ of the NiPAM units at $3.9 \mathrm{ppm}$ or to the backbone $\mathrm{CH} / \mathrm{CH}_{2}$ protons between 1.4 and $2.4 \mathrm{ppm}$ broaden and correspondingly, their intensity significantly decreases with temperature. This is attributed to a decrease in the mobility of the copolymer chain segments with the microgel deswelling above VPTT. However, the protons of the terpyridine-functionalized PEG side chains at $3.5 \mathrm{ppm}$ still yield an observable ${ }^{1} \mathrm{H}$ NMR peak indicating that some of the PEG repeat units (EG) are mobile at temperature higher than VPTT despite the collapse of the microgel. The temperature dependence of the fractions of mobile NiPAM ( $\mathrm{f}_{\text {NiPAM }}$ ) and $\mathrm{EG}\left(\mathrm{f}_{\mathrm{EG}}\right)$ units determined at $\mathrm{pH} 6$ (Figure $1 \mathrm{f}$ ) indicates that $70 \%$ of the incorporated PEGMA-Tpy groups remain mobile at $45^{\circ} \mathrm{C}$ whereas $f_{\text {NiPAM }}$ is close to zero above $38^{\circ} \mathrm{C}$. The protonation of terpyridine groups at $\mathrm{pH} 3$ does not affect the fraction of PEGMA-Tpy mobile units above the VPTT (Supporting Information, Figure S5). As a consequence, we can conclude that the major part of the Tpy ligands are located at the periphery of the microgels and available for further supramolecular interactions.

\section{Supramolecular-Driven Microgel Assembly}

Using microgels in contact with each other is certainly one of the most straightforward ways to establish that metalligand complex formation can indeed connect MG-Tpy microgels. Consequently, we put into contact compacted dry powder of microgels (around $50 \mathrm{mg}$ ) with $100 \mu \mathrm{L}$ of $10^{-3} \mathrm{M}$ $\mathrm{FeCl}_{2} \cdot 4 \mathrm{H}_{2} \mathrm{O}, \mathrm{CoCl}_{2}$ or $\mathrm{CaCl}_{2}$ respectively (Figure $2 \mathrm{a}$ ). The system is maintained at rest for $2 \mathrm{~h}$ at $25^{\circ} \mathrm{C}$, a time long enough to allow the diffusion of cations inside the microgels a

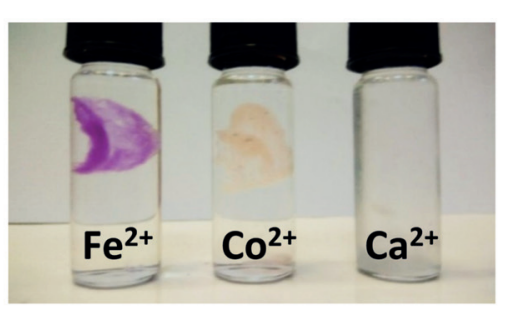

d

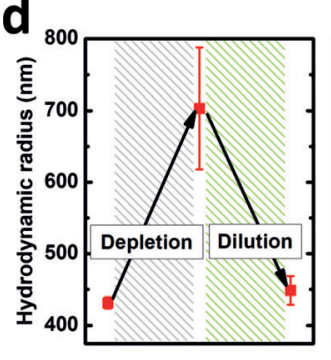

b

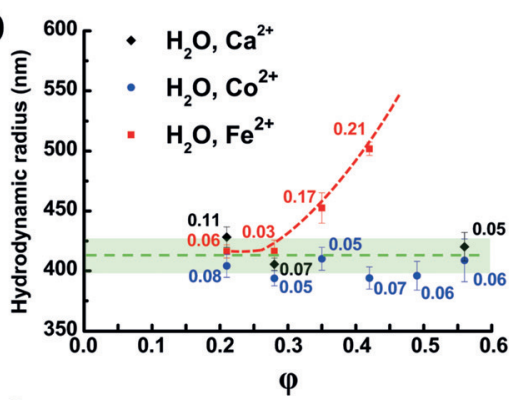

e

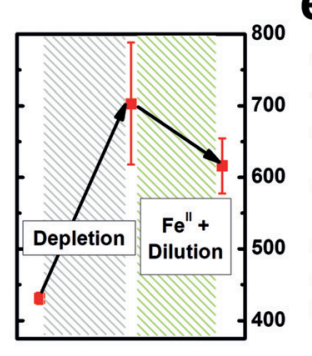

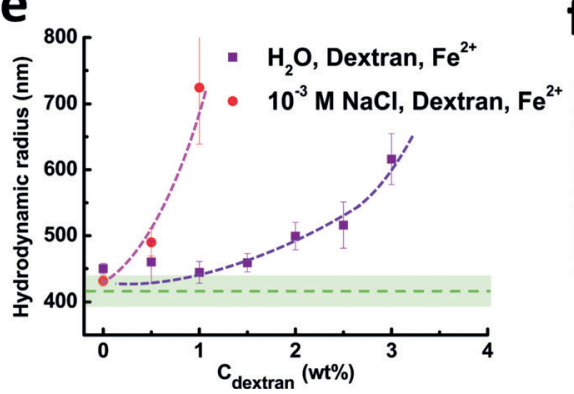

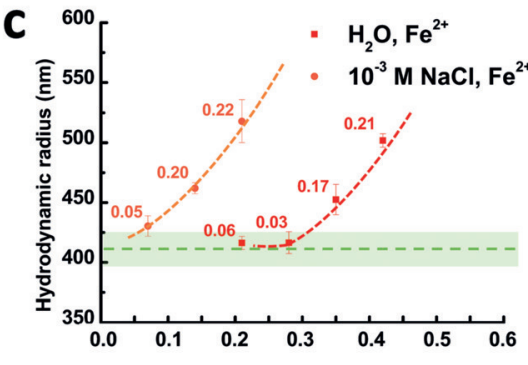

$\mathbf{f}$
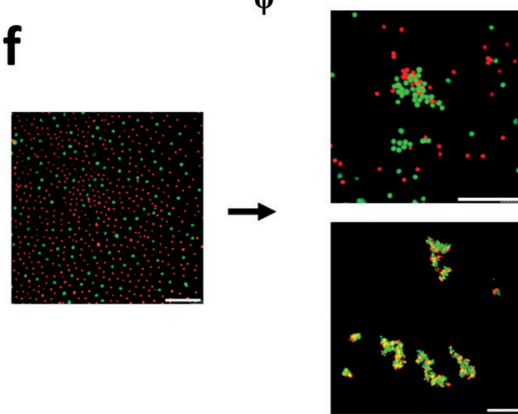

Figure 2. Assembly of MG-Tpy microgels induced by metallo-supramolecular chemistry at $25^{\circ} \mathrm{C}$. a) Formation of macrogel of microgels connected by supramolecular links, $\left[\mathrm{Fe}^{\prime \prime} \mathrm{Tpy}_{2}\right]^{2+}$ and $\left[\mathrm{Co}^{\prime \prime} \mathrm{Tpy}_{2}\right]^{2+}$. No macro-structure was observed in the case of a non-chelated cation $\left(\mathrm{Ca}^{2+}\right)$. b), c) Evolution of the average hydrodynamic radius, $R_{\mathrm{h}}$, of the MG-Tpy microgel aggregates as a function of the microgel volume fraction: b) Effect of the nature of the added cations and c) effect of the ionic strength. Labels denote the values of the polydispersity indexes, PDI, determined by cumulant analysis. Green dashed lines correspond to the average hydrodynamic radius of bare MG-Tpy microgels. d) Effect of depletant molecules (Dextran) on microgel assembly at $\varphi=0.014$ with $3 \mathrm{wt} \%$ of dextran in pure water at $25^{\circ} \mathrm{C}$ and evolution of the average hydrodynamic radius upon dilution without or with previous addition of iron(II). e) Combined effect of depletant molecules (dextran) and ionic strength on the supramolecular assembly of MG-Tpy microgels $(\varphi=0.014)$ at $25^{\circ} \mathrm{C}$. $\mathrm{f}$ ) CLSM pictures of bare (MG-TpyR + MG-TpyF microgels) (left) and supramolecularassembled MG-TpyR and MG-TpyF microgels with iron(II) at $\varphi=0.14$ in $\mathrm{H}_{2} \mathrm{O}, 10^{-3} \mathrm{M} \mathrm{NaCl}$ (up right) and at $\varphi=0.014, \mathrm{H}_{2} \mathrm{O}, 10^{-3} \mathrm{M} \mathrm{NaCl}, 1.5 \mathrm{wt} \%$ dextran (down right). Scale bar: $10 \mu \mathrm{m}$. 
powder. Then, $4 \mathrm{~mL}$ of water are added. The cations $\mathrm{Fe}^{\mathrm{II}}$ and $\mathrm{Co}^{\mathrm{II}}$ are chosen because both are readily and spontaneously chelated by terpyridine ligands to form highly stable thermodynamic bis-terpyridine complexes in water (association constant $\left.\beta_{2}>10^{16}\right) \cdot{ }^{[6,10]}$ After adding cations solution ( $\mathrm{Fe}^{\mathrm{II}}$ and $\left.\mathrm{Co}^{\mathrm{II}}\right)$, the respective pink and beige colors characteristic of the formed complexes were observed (Figure 2a). The structure of macrogels is maintained over time without significant release of microgels, in contrast to the control experiment performed with $\mathrm{Ca}^{2+}$ at the same concentration where microgels spontaneously disperse in water. Remarkably, these supramolecular macrogels exhibit a temperatureinduced deswelling above the VPTT of the microgels, that is, $33^{\circ} \mathrm{C}$ (Supporting Information, Figure S6). This swelling/ deswelling behavior is fully reversible and comparable to the one of dispersed microgels. From this result, we conclude that a supramolecular assembly of MG-Tpy microgels can be formed by introducing $\mathrm{Fe}^{\mathrm{II}}$ or $\mathrm{Co}^{\mathrm{II}}$, leading to a macrogel of microgels.

Considering the concept of colloidal molecule evocated in the introduction, a finer control over size of the MG-Tpy microgel assemblies is necessary. Figure $2 \mathrm{~b}-\mathrm{f}$ illustrates the influence of the key physico-chemical parameters, such as the microgel volume fraction $(\varphi)$, the ionic strength, and the effect of depletant molecules, necessary to induce the assembly of the microgels prior to the freezing of the structure using supramolecular links as depicted in Scheme 2. By centrifuging microgel dispersions at a given mass fraction we were able to prepare a large range of volume fraction of MG-Tpy microgel dispersions from near close-packing ( $\varphi=$ $0.56)$ to highly diluted $(\varphi=0.014)$. Similarly to the experiments conducted on the dry powder, we added at $T=25^{\circ} \mathrm{C}$ either $\mathrm{Fe}^{\mathrm{II}}$ or $\mathrm{Co}^{\mathrm{II}}$ as complexing cations of Tpy units. A control sample was also prepared by adding $\mathrm{Ca}^{2+}$ at the same ionic strength. To further ascertain the formation of supramolecular assemblies, samples were diluted to $\varphi=0.014$ and left under mild stirring overnight at $25^{\circ} \mathrm{C}$. Then, dynamic light scattering (DLS) measurements and confocal microscopy observations were performed to probe the aggregation state of the microgels. The effect of the nature of the metal cation on the supramolecular connections of microgels with $\mathrm{Fe}^{\mathrm{II}}$ and $\mathrm{Co}^{\mathrm{II}}$ in water as a function of the volume fraction is summarized in Figure $2 \mathrm{~b}$. The connection was probed in pure water ( $\mathrm{pH} \mathrm{6)}$ at $25^{\circ} \mathrm{C}$ for volume fractions, $\varphi$, ranging from 0.21 to 0.56 . Irrespective of $\varphi$, all microgel dispersions with added $\mathrm{Ca}^{2+}$ do not contain microgel aggregates, exhibit a homogeneous aspect and can flow under their own weight even at $\varphi=0.56$ (Supporting Information, Figure S7). In contrast, at an identical volume fraction the samples in which $\mathrm{Fe}^{\mathrm{II}}$ or $\mathrm{Co}^{\mathrm{II}}$ were added exhibit a gel-like behavior. Moreover, as in the case of macrogels, the addition of $\mathrm{Fe}^{\mathrm{II}}$ or $\mathrm{Co}^{\mathrm{II}}$ cations induced the appearance of either the pink $\left(\left[\mathrm{Fe}^{\mathrm{II}} \mathrm{Tpy}_{2}\right]^{2+}\right)$ or beige $\left(\left[\mathrm{Co}^{\mathrm{II}} \mathrm{Tpy}_{2}\right]^{2+}\right)$ color associated to the presence of the characteristic absorption bands observed by UV/Vis spectroscopy performed immediately after dilution (Supporting Information, Figure S8). ${ }^{[6,7]}$ These macroscopic observations are first hints supporting the formation of supramolecularcontrolled assemblies of microgels. Figure $2 \mathrm{~b}$ shows the size of the formed assemblies given in terms of equivalent hydrodynamic spheres (cumulant analysis) for each system one night after dilution $(\varphi=0.014)$. In the case of $\mathrm{Ca}^{2+}$ (not chelated by Tpy units) the average hydrodynamic radius is similar to that of the bare MG-Tpy microgel whatever the volume fraction. In the case of iron(II), we clearly identify the formation of aggregates of MG-Tpy microgels characterized by an increase of the average hydrodynamic radius concomitant to an increase of the polydispersity index (PDI) for volume fractions $\varphi \geq 0.35$. We can thus confirm that the microgel assemblies are metallo-supramolecularly frozen by the formation of $\left[\mathrm{Fe}^{\mathrm{II}} \mathrm{Tpy}_{2}\right]^{2+}$ complexes. However, in the case of $\mathrm{Co}^{\mathrm{II}}$, the values of the measured average hydrodynamic radius are similar to the ones obtained for individual microgels in the range of investigated volume fraction. This result seems to be inconsistent with the macroscopic observations performed just after dilution of the samples. Actually, the disassembly of microgels observed in the case of $\mathrm{Co}^{\mathrm{II}}$ may result from the dynamics of the formed complexes. Indeed, even though both $\mathrm{Fe}^{\mathrm{II}}$ and $\mathrm{Co}^{\mathrm{II}}$ exhibit a very strong affinity with terpyridine units $\left(\beta_{2}>10^{16}\right)$, they highly differ by their kinetics of dissociation of the bis-complexes. The cobalt-based complex, $\left[\mathrm{Co}^{\mathrm{II}} \mathrm{Tpy}_{2}\right]^{2+}$, displays a more pronounced lability compared to the iron-based one, $\left[\mathrm{Fe}^{\mathrm{II}} \mathrm{Tpy}_{2}\right]^{2+}\left(k_{-2}, \mathrm{Co}^{\mathrm{II}}=\right.$ $4.10^{-2} \min ^{-1}$ and $\left.k_{-2}, \mathrm{Fe}^{\mathrm{II}}=10^{-5} \mathrm{~min}^{-1}\right) .^{[10,11]}$ This means that the characteristic dissociation frequency of the cobalt(II) biscomplexes is higher than that of the iron(II) based ones. Thus, after dilution of the samples to $\varphi=0.014$, dissociation events between connected microgels lead to the redispersion of microgels. These results do not necessarily imply that iron(II) induces more connections between microgels than cobalt(II); it rather means that iron(II) based complexes are much more stable over time. Finally, kinetically frozen MG-Tpy microgel assemblies induced by $\left[\mathrm{Fe}^{\mathrm{II}} \mathrm{Tpy}_{2}\right]^{2+}$ supramolecular complexes can instantly form in pure water at $25^{\circ} \mathrm{C}$ when the microgel volume fraction is higher than $\varphi=0.35$ (see kinetics experiments in the Supporting Information, Figure S9). In what follows, the physico-chemical parameters controlling MGTpy microgel assemblies are only investigated in the presence of $\mathrm{Fe}^{\mathrm{II}}$ cations.

The decrease of the electrostatic repulsions between microgels allows increasing the probability of contact at a given volume fraction. Figure $2 \mathrm{c}$ shows the evolution of the average hydrodynamic radius of the formed assemblies supramolecularly linked with iron(II) at $25^{\circ} \mathrm{C}$ for a volume fraction between $\varphi=0.07$ and $\varphi=0.56$ in pure water and in $10^{-3} \mathrm{M} \mathrm{NaCl}$. It is worth noting that the ionic strength does not affect the colloidal stability of the dispersed MG-Tpy microgels. Once again, an increase of both the average hydrodynamic radius and PDI of the microgel aggregates was observed after addition of $\mathrm{Fe}^{\mathrm{II}}$ in the solution. However, this increase occurs from a volume fraction of $\varphi=0.14$ lower than that observed in pure water $(\varphi>0.35)$. The CLSM images presented in Figure $2 \mathrm{f}$ (upper right) confirms the formation of assemblies of MG-TpyR and MG-TpyF microgels at $\varphi=$ 0.14 in $10^{-3} \mathrm{M} \mathrm{NaCl}$ solution. It is thus possible to decrease very significantly the extent of electrostatic repulsions by addition of salt, hence increasing the probability of contact between microgels at lower volume fractions than in pure water even if the charge density of microgels is quite low in 
these conditions (Figure 1b). Then, the decrease of electrostatic repulsions enables the formation of metallo-supramolecular frozen assemblies of MG-Tpy microgels in water at $25^{\circ} \mathrm{C}$ above a critical volume fraction $\varphi=0.14$. Below this value, the presence of salt is not sufficient to make microgels come close enough to build aggregates as iron(II) is added.

To aggregate microgels at a lower volume fraction $(\varphi=$ 0.014 ) before adding iron(II), an attractive depletion potential between them was introduced by adding dextran chains $\left(\mathrm{M}_{\mathrm{w}}=100.000 \mathrm{~g} \mathrm{~mol}^{-1}\right)$ in a MG-Tpy dispersion. ${ }^{[12]}$ Addition of dextran chains at $3 \mathrm{wt} \%$ to a MG-Tpy dispersion in pure water at $25^{\circ} \mathrm{C}$ successfully enables to form aggregate microgels (Figure $2 \mathrm{~d}$ left). However, they disassemble upon dilution in water to form again a microgel solution. The addition of iron(II) to a dispersion of depletion-driven microgel aggregates enables to freeze the aggregates by metallo-supramolecular links and maintain the structure upon dilution (Figure $2 \mathrm{~d}$ right and Figure $2 \mathrm{f}$ down right). Lastly, we show that a combination of depletion and partial screening of repulsive electrostatic repulsions followed by subsequent addition of iron(II) enables to perform metallosupramolecular assemblies of MG-Tpy at both low volume fraction $\varphi=0.014$ and low concentration of depletant dextran molecules ( $0.5 \mathrm{wt} \%$; Figure $2 \mathrm{e})$. Therefore, depletion-induced attraction between microgels appears as an efficient pathway to favor contact between them at low volume fraction.

\section{Responsive Disassembly of Microgels}

We took advantage of the supramolecular nature of the links to open the metal-ligand complexes in response to an external stimulus with the aim of dissociating the microgel assemblies. Competitor molecules or $\mathrm{pH}$ are among the stimuli commonly used to cleave the terpyridine-based supramolecular complexes incorporated in macromolecular systems ${ }^{[13]}$ Here, we studied the possibility to oxidize iron(II) embedded between terpyridine units into iron(III) using potassium persulfate (KPS) as an original route to dissociate the metal-terpyridine complex and consequently to break microgel assemblies (Scheme 2). Indeed, it is reported that iron(III)/ bis-terpyridine complexes are not kinetically stable and exhibit a very high lability so that microgel aggregates disassembly can be expected. ${ }^{[14]}$ Oxidation of $\mathrm{Fe}^{\mathrm{II}}$ by KPS is possible because the standard redox potential of the $\left[\mathrm{Fe}^{\mathrm{III}} \mathrm{Tpy}_{2}\right]^{3+} /\left[\mathrm{Fe}^{\mathrm{II}} \mathrm{Tpy}_{2}\right]^{2+}$ couple $(1.02 \mathrm{~V}$ vs. standard hydrogen electrode (SHE); Supporting Information, Figure S10) is lower than that of the $\mathrm{S}_{2} \mathrm{O}_{8}{ }^{2-} / \mathrm{SO}_{4}{ }^{2-}$ couple (2.08 V vs. SHE). Figure 3 presents UV/Vis and DLS experiments performed on microgels aggregates samples prior and after addition of KPS. The absorption band at $567 \mathrm{~nm}$ characteristic of the $\left[\mathrm{Fe}^{\mathrm{II}} \mathrm{Tpy}_{2}\right]^{2+}$ complex at the molecular scale disappears after adding the oxidant molecules (Figure $3 \mathrm{a}$ ). Accordingly, at the microgel scale, DLS measurements show that the microgel aggregates break into individual microgels (Figure $3 \mathrm{~b}$ ) after $3 \mathrm{~h}$ (Supporting Information, Figure S11). Finally, we demonstrated the reversibility of the assembly-disassembly process by successively adding iron(II) to freeze the microgel

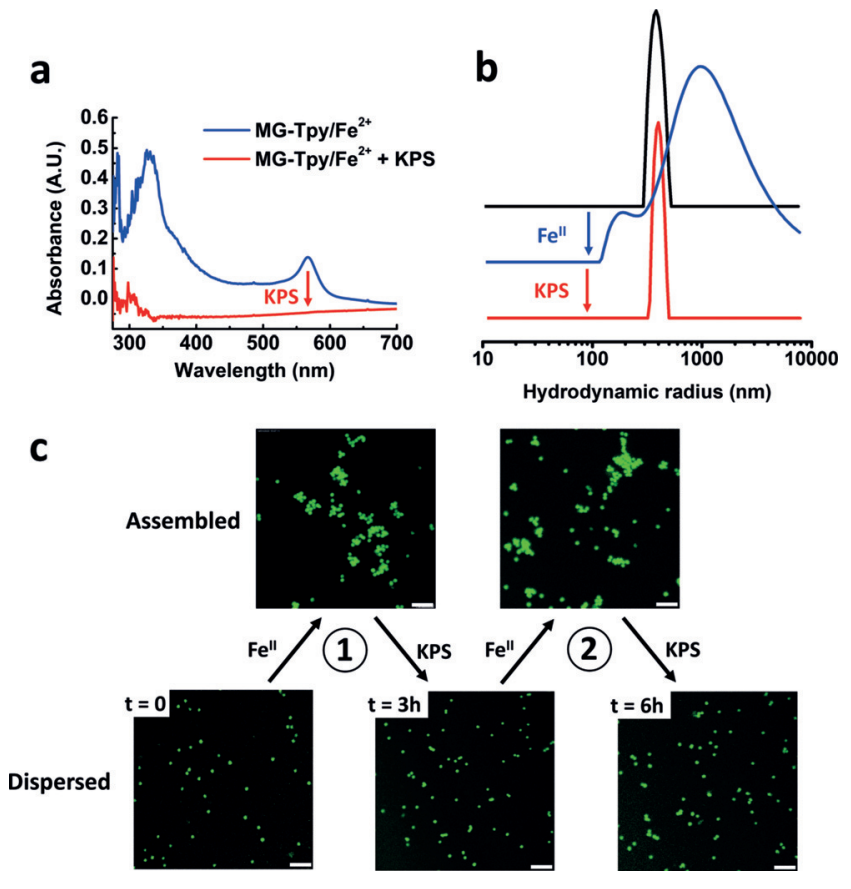

Figure 3. Responsive disassembly of microgels aggregates $(\varphi=0.14$ in $\mathrm{H}_{2} \mathrm{O}, 10^{-3} \mathrm{M} \mathrm{NaCl}$ ). a) UV/Visible spectra of assembled and disassembled microgel dispersion. b) Intensity size distribution of bare MG-Tpy microgel dispersions, assembled MG-Tpy microgel dispersions with $\mathrm{Fe}^{\mathrm{II}}$ and disassembled MG-Tpy microgel dispersions upon addition of KPS. c) Reversibility of the assembly-disassembly process shown by confocal microscopy of over two cycles. Scale bar: $5 \mu \mathrm{m}$.

assemblies and KPS to cleave the metal-terpyridine complex and release microgels in solution. The reversibility was shown by confocal images (Figure 3c) and supported by dynamic light scattering experiments performed at each stage (Supporting Information, Figure S12).

\section{Toward New Supramolecular Materials}

The systematic study of the microgel assemblies paves the way to the development of novel 1D, 2D, or 3D supramolecular organic materials in which microgels are the building blocks. On the one hand, a concentrated dispersion of MGTpy microgels $(\varphi=0.5)$ can be extruded in an iron(II) aqueous solution to form a filament (Figure $4 \mathrm{a}$; Supporting Information, Movie S1). After extrusion, the microgels filament was instantaneously frozen by the formation of $\left[\mathrm{Fe}^{\mathrm{II}} \mathrm{Tpy}_{2}\right]^{2+}$ supramolecular links between close-packed microgels as outlined by the appearance of the pink color. The macrostructure resists to mechanical shear induced by a stirring bar. On the contrary, an extrusion realized with an identical MG-Tpy microgels dispersion in pure water led to the complete dispersion of the microgels (Supporting Information, Movie S2). As presented before with micro-assemblies of microgels, the disassembly of this macro-structure may be triggered by addition of KPS (Supporting Information, Figure S13). By taking advantage of the spontaneous adsorption of NiPAM-based MG-Tpy at air-water interface, air bubbles stabilized by the microgels are formed (Fig- 


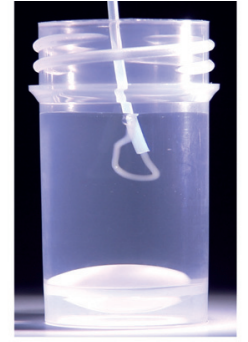

b

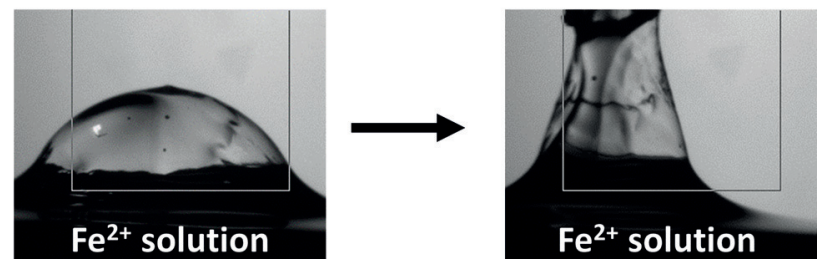

Figure 4. Macroscopic observations of the MG-Tpy microgel aggregation $(\varphi=0.5)$ induced by metallo-supramolecular chemistry at $25^{\circ} \mathrm{C}$ with $\mathrm{Fe}^{2+}$. a) Microgel filament obtained by extrusion of a microgel dispersion into a $\mathrm{Fe}^{2+}$ solution (see also the Supporting Information, Movie S1). b) Left: A microgel bubble was deposited onto a thin layer of $\mathrm{Fe}^{2+}$ solution; right: after migration of $\mathrm{Fe}^{2+}$ ions into the microgel membrane, a pipette was used to mechanically stress the membrane (Supporting Information, Movie S3).

ure $4 \mathrm{~b}) .^{[15]}$ The crosslinking of the thin film occurs by depositing the bubble on an iron(II) aqueous solution (Figure $4 \mathrm{~b}$, left)

Indeed, iron(II) ions can diffuse through the film inducing metallo-supramolecular links between microgels in close contact at the interface. A mechanical stress of the crosslinked microgel thin film clearly demonstrates the formation of a microgel skin (Figure $4 \mathrm{~b}$, right; Supporting Information, Movie S3) contrary to a classical bubble stabilized by MGTpy microgels in absence of iron(II) (Supporting information, Movie S4).

\section{Conclusion}

By combining colloidal assembly and supramolecular chemistry, we have demonstrated a strategy to design reversible metallo-supramolecular assemblies of thermoresponsive microgels in water. To this end, a fine-tuning of the building block microgels is achieved by introducing accessible terpyridine-based supramolecular ligands into the microgel network. Next, we showed the possibility to prepare frozen macro-assemblies such as macrogels or aggregates of microgels maintained by the formation of metallo-supramolecular links involving the metal coordination complex. The physicochemical parameters (microgel volume fraction, ionic strength, metal cations, and depletant molecules) have been screened to define rules for supramolecular assembly of microgels. Lastly, we emphasize on the possibility to induce a responsive disassembly of the connected microgels by oxidation of the metallo-supramolecular links, $\left[\mathrm{Fe}^{\mathrm{II}} \mathrm{Tpy}_{2}\right]^{2+}$, between connected microgels. As a proof-of-concept, the elaboration of new supramolecular materials resulting from microgels as building blocks has been explored, leading to the formation of injectable macrogels or supramolecular crosslinked membranes. This assemble-freeze-disassemble strategy can serve as a starting point for future research owing to the versatility of both the microgels and the metallosupramolecular chemistry.

\section{Acknowledgements}

The authors gratefully acknowledge the financial support of CNRS, ESPCI, and the PhD school of Sorbonne Universite (ED 397, Sorbonne Université) for the PhD fellowship funding of J. Es Sayed. The authors thank Christophe Meyer for his help in organic chemistry, Bruno Bresson for technical advice on SEM experiments, Nadège Pantoustier and Philippe Devilliers for fruitful discussion. The authors thank the microscopy platform of Institut Pierre Gilles de Gennes for technical advice on CLSM.

\section{Conflict of interest}

The authors declare no conflict of interest.

Keywords: colloid assembly - microgels - responsive materials . supramolecular chemistry $\cdot$ terpyridine complex

[1] a) V. N. Manoharan, Science 2015, 349, 1253751; b) N. Vogel, M. Retsch, C.-A. Fustin, A. del Campo, U. Jonas, Chem. Rev. 2015, 115, 6265-6311; c) D. Morphew, D. Chakrabarti, Curr. Opin. Colloid Interface Sci. 2017, 30, 70 - 80; d) K. Zhao, T. G. Mason, Rep. Prog. Phys. 2018, 81, 126601.

[2] a) M. Gerth, I. K. Voets, Chem. Commun. 2017, 53, 4414-4428; b) M. J. Solomon, Langmuir 2018, 34,11205-11219; c) Q. Chen, S. C. Bae, S. Granick, Nature 2011, 469, 381 -384.

[3] a) V. E. Shashoua, R. G. Beaman, J. Polym. Sci. 1958, 33, $101-$ 117; b) R. H. Pelton, P. Chibante, Colloids Surf. 1986, 20, $247-$ 256; c) B. R. Saunders, B. Vincent, Adv. Colloid Interface Sci. 1999, 80,1-25; d) R. Pelton, Adv. Colloid Interface Sci. 2000, 85, $1-33$.

[4] a) R. H. Pelton, H. M. Pelton, A. Morphesis, R. L. Rowell, Langmuir 1989, 5, 816-818; b) A. Z. Pich, S. Berger, O. Ornatsky, V. Baranov, M. A. Winnik, Colloid Polym. Sci. 2009, 287, 269-275; c) A. Z. Pich, W. Richtering in Chemical Design of Responsive Microgels, Springer, Heidelberg, New York, 2010; d) F. A. Plamper, W. Richtering, Acc. Chem. Res. 2017, 50, $131-$ 140 ; e) J. Es Sayed, C. Lorthioir, P. Perrin, N. Sanson, Soft Matter 2019, 15, 963-972.

[5] a) K. Han, D. Go, T. Tigges, K. Rahimi, A. J. C. Kuehne, A. Walther, Angew. Chem. Int. Ed. 2017, 56, 2176-2182; Angew. Chem. 2017, 129, 2208-2214; b) K. Han, D. Go, D. Hoenders, A. J. C. Kuehne, A. Walther, ACS Macro Lett. 2017, 6, 310-314; c) P. Wang, Q. Yang, Z. Ye, C. Zhao, J. Yang, Macromol. Chem. Phys. 2017, 218, 1700280; d) I. Antoniuk, D. Kaczmarek, A. Kardos, I. Varga, C. Amiel, Polymer 2018, 10, 566. 
[6] a) E. C. Constable, Adv. Inorg. Chem. 1986, 30, 69-121; b) M. Maestri, N. Armaroli, V. Balzani, E. C. Constable, A. M. W. Cargill Thompson, Inorg. Chem. 1995, 34, 2759-2767; c) A. S. Abd-El-Aziz, C. E. Carraher, C. V. Pittman, J. E. Sheats, M. Zeldin, in A Half-Century of Metal- and Metalloid-Containing Polymers, Vol. 1, Wiley-Interscience, Hoboken, 2003; d) U. S. Schubert, A. Winter, G. R. Newkome in Terpyridine-Based Materials, Wiley-VCH, Weinheim, 2011.

[7] a) U. S. Schubert, O. Hien, C. Eschbaumer, Macromol. Rapid Commun. 2000, 21, 1156-1161; b) B. G. G. Lohmeijer, U. S Schubert, Angew. Chem. Int. Ed. 2002, 41, 3825-3829; Angew. Chem. 2002, 114, 3980-3984; c) S. Schmatloch, U. S. Schubert, Macromol. Symp. 2003, 199, 483-497; d) A. Winter, U.S. Schubert, Chem. Soc. Rev. 2016, 45, 5311-5357; e) S. Piogé, C.-A. Fustin, J.-F. Gohy, Macromol. Rapid Commun. 2012, 33, 534-539.

[8] a) Y.-T. Chan, S. Li, C. N. Moorefield, P. Wang, C. D. Shreiner, G. R. Newkome, Chem. Eur. J. 2010, 16, 4164-4168; b) M. Gerth, M. Bohdan, R. Fokkink, I. Voets, J. van der Gucht, J. Sprakel, Macromol. Rapid Commun. 2014, 35, 2065-2070; c) J. Lee, E. J. Choi, I. Varga, P. M. Claesson, S.-H. Yun, C. Song, Polym. Chem. 2018, 9, 1032-1039.

[9] a) R. B. Martin, J. A. Lissfelt, J. Am. Chem. Soc. 1956, 78, $938-$ 940 ; b) P. Offenhartz, P. George, G. P. Haight, J. Phys. Chem. 1963, 67, 116- 118 .

[10] a) R. Hogg, R. G. Wilkins, J. Chem. Soc. 1962, 341 -350; b) R. H. Holyer, C. D. Hubbard, S. F. A. Kettle, R. G. Wilkins, Inorg. Chem. 1966, 5, 622-625.
[11] a) I. M. Henderson, R. C. Hayward, J. Mater. Chem. 2012, 22, 21366-21369; b) I. M. Henderson, R. C. Hayward, Polym. Chem. 2012, 3, 1221-1230.

[12] a) S. Asakura, F. Oosawa, J. Chem. Phys. 1954, 22, 1255-1256; b) S. Asakura, F. Oosawa, J. Polym. Sci. 1958, 33, $183-192$; c) J. Clarke, B. Vincent, J. Chem. Soc. Faraday Trans. 1 1981, 77, 1831 -1843; d) A. Fernández-Nieves, A. Fernández-Barbero, B. Vincent, F. J. de las Nieves, Prog. Colloid Polym. Sci. 2000, 115, 134-136; e) A. Fernández-Nieves, A. Fernández-Barbero, B. Vincent, F. J. de las Nieves, J. Chem. Phys. 2003, 119, 1038310388; f) M. Rasmusson, A. Routh, B. Vincent, Langmuir 2004, $20,3536-3542$.

[13] a) M. Chiper, D. Fournier, R. Hoogenboom, U. S. Schubert, Macromol. Rapid Commun. 2008, 29, 1640-1647; b) B. G. G. Lohmeijer, U. S. Schubert, Macromol. Chem. Phys. 2003, 204, 1072-1078.

[14] a) Y.-W. D. Chen, K. S. V. Santhanam, A. Bard, J. Electrochem. Soc. 1981, 128, 1460-1467; b) T. Satyanarayana, N. R. Anipindi, React. Kinet. Catal. Lett. 1992, 47, 333-341; c) G. Bellér, G. Lente, I. Fábián, Inorg. Chem. 2017, 56, 8270-8277.

[15] a) J. Zhang, R. Pelton, Langmuir 1999, 15, 8032-8036; b) V. Schmitt, M. Destribats, R. Backov, C. R. Phys. 2014, 15, $761-$ 774. 